\title{
Cold Supply Chain Processes in a Fruit-and-Vegetable Collaborative Network
}

\author{
M. Victoria de-la-Fuente and Lorenzo Ros \\ Universidad Politécnica de Cartagena, ETSII, \\ Campus Muralla del Mar, 30202 Cartagena, Spain \\ \{marivi.fuente, lorenzo.ros\} @upct.es
}

\begin{abstract}
The work presented in this paper focuses on the construction of a prototype for strategic design of nodes in a logistics network (PROCONET project). It incorporates the necessary concepts, models and supporting tools related to the design of the process flow and the choice of technology. The operation of the prototype will be validated with global supply chain processes for perishable products. Global supply chain processes will consider both full loads and groupages. Special attention will be given to the impact of INCOTERM agreements. The prototype will support intermodal logistics processes as an added value.
\end{abstract}

Keywords: Cold chain, Collaborative network, Perishable goods.

\section{Introduction}

In the last thirty years the fruit-and-vegetable sector has become the first Spanish agriculture sector in terms of production and export value. Driven by strong competition, this dynamic area must continuously incorporate new methods and technologies.

As such, an ongoing effort has to be made by agricultural companies to implement innovative measures which add value to the sector and make it capable of appropriately responding to consumers' demands, of successfully facing competition and of maintaining leadership via new products and new forms of presenting them.

It is in this context of innovation and new technologies where the PROCONET Research Project is defined, initiated due to the need for improvements in logistics and transport of perishable goods (as discovered by the companies in this segment). A prototype of strategic storage nodes will be designed in a collaborative network framework, which facilitates the operation of the cold chain and transportation of products while ensuring traceability and food safety throughout the whole logistic process.

This paper is organized as follows: Section 2 presents a brief review of collaborative networks, their characteristics, their coordination of activities and the information mechanisms inside them. Section 3 deals with current issues in the Spanish fruit-and-vegetable sector. Section 4 discusses the objectives, the integration methodology and the framework for the fruit-and-vegetable collaborative network to 
be developed in the project, and proposes the PROCONET architectural design and components of the fruit-and-vegetable collaborative network, information systems and network data exchange techniques. Section 5 presents the main conclusions and innovation aspects of the PROCONET project.

\section{Collaborative Networked Organizations}

Participation in networks has become very important for any organization that strives to achieve a differentiated competitive advantage. Among the wide variety of existing networks, collaborative networks are especially relevant. These have emerged over the last few years as a result of the challenges faced by both the business and scientific world, since collaboration has become the key issue to rapidly answer market demands in manufacturing companies through sharing competence and resources [5].

A collaborative network $(\mathrm{CN})$ is constituted by a variety of entities (e.g. organizations and people) that are largely autonomous, geographically distributed, and heterogeneous in terms of their operating environment, culture, social capital and goals. Nevertheless, these entities collaborate to better achieve compatible goals, using ICT for supporting the development of collaborative business opportunities [3].

As dynamic inter-organizational models, CNs must display a distributed business process management system to support the means for obtaining, providing and managing production-related information from and about $\mathrm{CNs}$, enabling enterprises to conduct their logistics more efficiently, and working better in an integrated and virtual environment [9]. In this context, communication mechanisms play a vital role, alongside coordination to support the exchange of information between interdependent activities / processes and among $\mathrm{CN}$ enterprises [2].

For this reason, the advantages in the ICT that support the concept of collaborative networks have allowed enterprises to move to more cooperative information-driven environments. Enterprise knowledge sharing (know-how), open source / web-based applications, and common best practices are ways to achieve both the concept of integrated enterprise and the implementation of collaborative networked enterprises for the manufacturing industry [5].

Finally, it must be noted that a growing number of collaborative networked organization forms are emerging as a result of the continuous advances in the field of ICT, which contributes to help SMEs face current social and market challenges. CNs are already recognized as an important survival instrument for organizations in a period of turbulent socio-economic changes $[3,5]$.

\section{The Fruit-and-Vegetable Spanish Sector: Problems and Necessities}

In the last thirty years the fruit and vegetable sector has become the first sector of Spanish agriculture in terms of production value. Spain is the major producer of fruits and vegetables for consumption in fresh and the major exporter of these products. 
The fruit-and-vegetable sector is extremely dynamic. It is continuously incorporating new methods and modern technologies, due to heavy domestic competition, and especially because of the development that is occurring in other regions and countries. An increasingly globalized market and competition from producers and distributors from other regions within, and outside of, the European Union compels a continuous effort to adopt competitive measures which add value to the sector and make it possible to respond to consumers' demands, to face foreign competition, to maintain the leadership of the Spanish sector and to increase its market share by introducing new products, and new ways of presenting them [6].

Spanish exportation of fruit and vegetables in recent campaigns has totalled more than 9 million tons. The main countries of destination are other member countries of the European Union, which receive more than $87 \%$ of these exports. Most of these shipments are dispatched by land, especially by road, using refrigerated vehicles to transport loads at a controlled temperature.

Analysis of Spanish production areas, trends in consumption and markets; experience in distribution and logistics; even the expansion to 27 European Union member states, with a market of 500 million consumers, all seems to confirm an increase in the demand of transport by trucks at controlled temperatures (refrigerated lorries), for shipments of fruit-and-vegetable produce and other logistic services associated to it $[6,8]$.

However, the sector must also confront a number of problems, both internal (precarious generational relief, progressive decrease of resources such as water and land, etc.) and external (production from third countries at lower costs and less Customs control, etc.).

A conclusion can be drawn from all the above: by trying to balance market preferences and agricultural reality, the fruit-and-vegetable sector faces constant challenge. For the transformation of this sector the development of innovative solutions will be of great importance to keep its leadership positioning. This goal can be achieved by primarily focusing on aspects which enable producers to have an advantageous position over large distribution chains.

\section{The PROCONET Project}

When analyzing the fruit-and-vegetable marketing process as a whole, from the point where the decision is made to grow a certain kind of product to the stage when it reaches the final consumer, a wide range of innovations are used as a response to demands from markets and consumers, as well as new proposals in production, distribution and transport.

In this process, relations are established among the agents involved in the food supply chain: producers, growers, exporters, importers, haulers, etc., which must be adapted and managed from a collaborative business model.

The organizational model "Collaborative Network" is composed of a variety of entities (organizations and individuals) largely autonomous, geographically distributed, all collaborating to better achieve common / compatible goals, with the interactions among them supported by computer networks; and with common patterns, such as autonomous entities from varied locations, driven by common goals/intentions to be 
achieved by collaboration, and operationally based on agreed principles and interoperable infrastructures which allow them to cope with their heterogeneity $[3,5]$.

As aforementioned, internal and external competition in the fruit and vegetable industry obliges those companies involved to continually innovate in terms of range of products, growing techniques and product presentation, and to improve in such aspects as food handling, storage systems, loading and unloading techniques, etc. There are various reasons behind all these innovations, but they are mainly determined by consumers and food safety rules, and must respond to the different problems posed by the agents/companies in the sector.

The pursuit of the PROCONET Project research team may be defined as "comprehensive traceability of agri-food road transport at controlled temperature", which, on the basis of logistic processes (either full loads or groupages) may grant access to experimenting with electronic CMRs by means of controlling technological variables involved in the said logistical processes.

Today's existing traceability models for the food sector focus on certain products (milk, eggs, beef, transgenic products, etc.). The food safety and traceability model presented in this paper results from the lack of legislation in the agri-food sector and also from recommendations issued by both Spanish and European organizations during the last decade $[1,7,11]$.

The PROCONET Project focuses on the construction of a prototype for strategic design of nodes in a logistics network. It incorporates the necessary concepts, models and supporting tools related to the design of the process flow and the choice of technology. The operation of the prototype will be validated with global supply chain processes for perishable products. Global supply chain processes will consider both full loads and groupages. Special attention will be given to the impact of INCOTERM agreements. The prototype will support intermodal logistics processes as an added value.

The project will develop a platform for knowledge management in a collaborative fruit-and-vegetable network, which supports the communication processes within that network (see Figure 1). Connected to the Operations Planning and Control System application run by each of the member companies in the collaborative network, this platform will design and manage such crucial elements as:

(a) Route maps (scheduled departures and arrivals, checkpoints, etc.) linked to existing applications may display real-time information on the location of transport units and related data (dispatch time, average speed, cargo temperature, etc.).

(b) Route maps connected with invoicing systems in such a way that the logistics company may invoice for the service given at the time of collection / delivery.

(c) Transport management and management of fleet condition, resource utilization, reduction of polluting emissions, data control.

The PROCONET platform, or integrated model for communication between transport systems and logistics companies, will allow, through GPS (Global Positioning System), to know where the merchandise is at any given time, facilitating its transport and delivery in terms of traceability and food safety. 


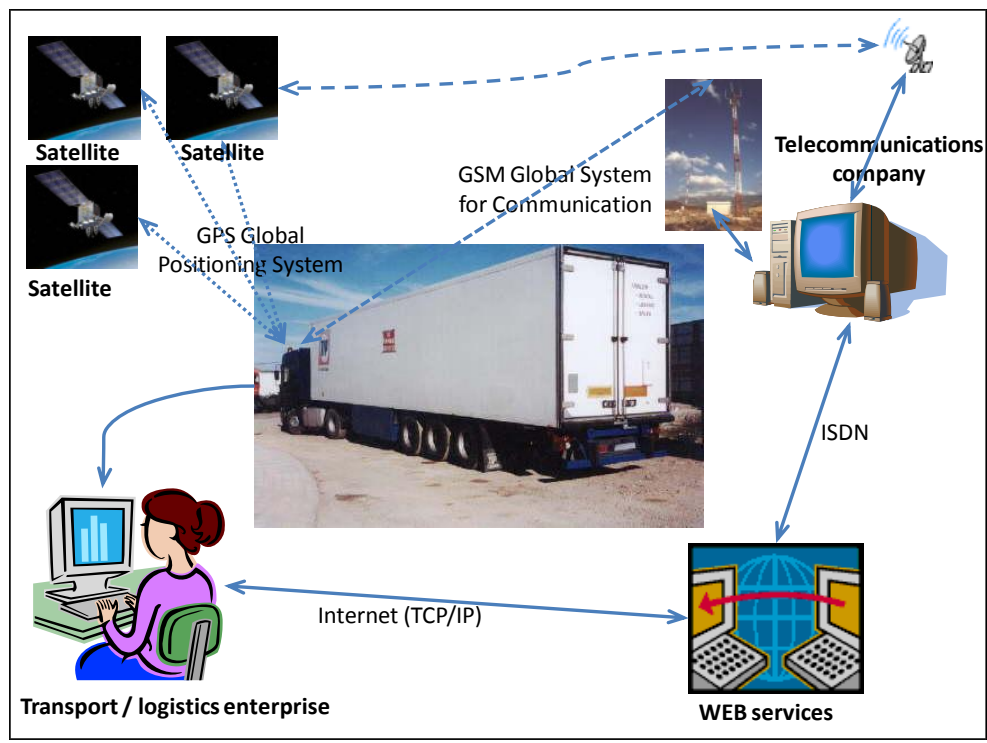

Fig. 1. Interconnected electronic information PROCONET platform

\subsection{Technical Objectives of the PROCONET Project}

The technical objectives targeted by this project form a continuum from business requirements up to evaluation of alternatives:

1. To inventory systems and equipment being used, likely to be used or likely to be developed for the Cold Supply Chain.

2. To design the necessary processes required for handling of loads in the groupages storage node for transportation by the Cold Supply Chain.

3. To define a model for traceability and food safety of fruit-and-vegetable products in the transport process of the cold supply chain.

4. To define a methodology which relates business decisions on transport (inventory records, suppliers' orders records and customers' orders records) with the technical requirements of the technology used in the Cold Chain.

5. To Identify and parameterize those variables likely to be present in a cold supply chain and their interaction with other agents in the chain.

6. To develop an initial traceability and food safety prototype for fruit-andvegetable products in the logistic processes of the cold supply chain.

7. To develop a second transport safety prototype, based on INCOTERMS and demonstrate the feasibility of an electronic CMR.

8. To integrate both prototypes in such a way that a small transport business may evolve into a logistics company.

9. To assess and evaluate the developed prototypes.

10. To diffuse the conclusions of the completed prototyping work. 


\subsection{Methodology for the PROCONET Project}

As stated by several authors [4,5], in Collaborative Networks there is not a single formal modelling methodology, tool or approach that may adequately cover all perspectives (no universal language for all problems).

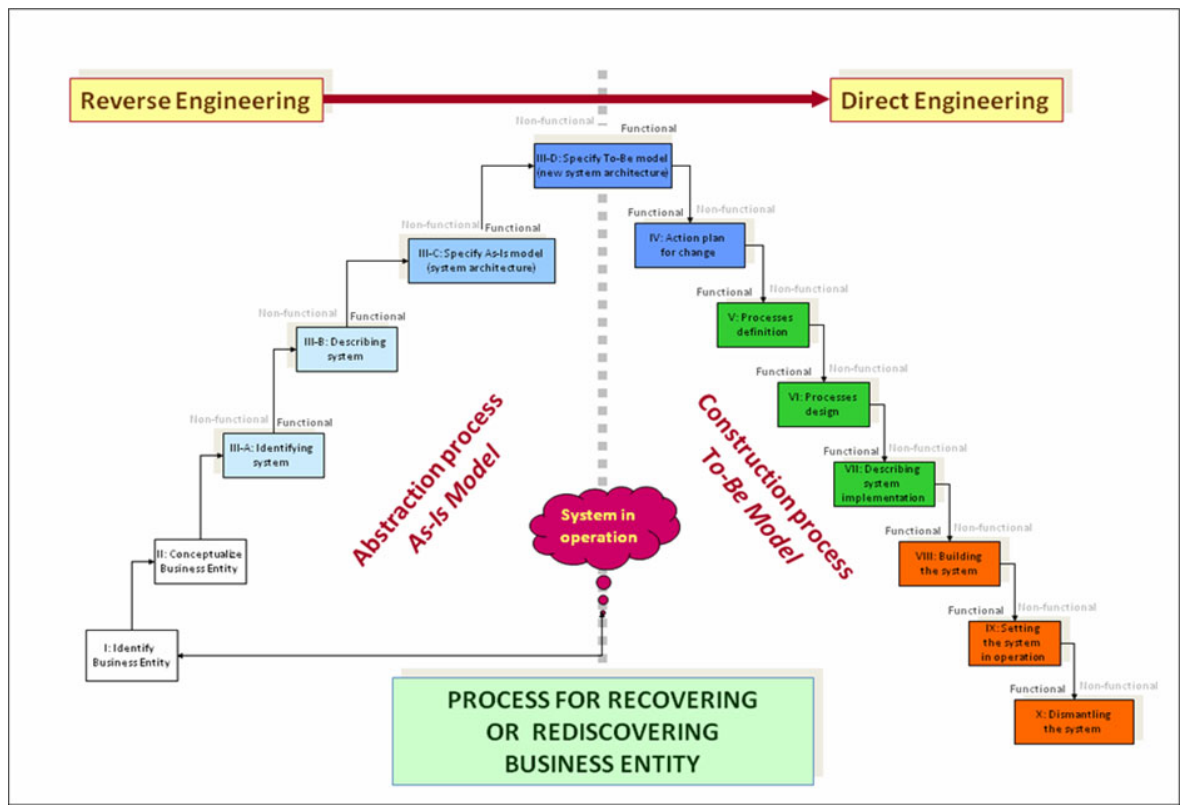

Fig. 2. Phases and stages of the ERE-GIO methodology

Therefore, for the development of a fruit-and-vegetable collaborative network which allows an appropriate paradigm and approach for different enterprise information systems of cold chain integration and collaboration, the research team are working with the ERE-GIO methodology [10], based on Integrated Information Architectures, and also on their own experience in designing and managing different enterprise information systems. The ERE-GIO methodology will allow the establishment of a modelling framework for CNs which integrates multiple perspectives, because this methodology presents a life cycle approach based on the "As-is" model as well as on the "To-be" model (Figure 2).

This model will be used to develop an approach to the cold supply chain from an endogenous $\mathrm{CN}$ perspective, made and mapped into different dimensions (structural, functional, etc.). This double-model methodology will also be used to integrate the GPS system and the platform that will support cold chain processes, whilst analyzing the performance and constraints of the traceability and safety prototype, and further implementation in the collaborative network. 


\subsection{Innovation in the Cold Supply Chain}

Innovation is a complex and diversified activity involving many components interacting and acting as sources of new ideas. The PROCONET project is focused on incremental technological innovations, i.e. improvements that are made to a service or an existing process in order to increase the benefits for the chain or the network.

In this project, innovation is oriented towards four large areas (see Table 1), which for the fruit-and-vegetable collaborative network translates into the following factors: renewal and expansion of the productive processes and the range of services, changes in organization and in management, and consequences of the feasibility of the electronic CMR.

Table 1. Technological innovation of the PROCONET project

\begin{tabular}{|l|l|}
\hline $\begin{array}{l}\text { Fruit-and- } \\
\text { vegetable } \\
\text { Sector }\end{array}$ & $\begin{array}{l}\text { Traceability control of fruit-and-vegetable products during the } \\
\text { transport and handling phases. }\end{array}$ \\
\hline $\begin{array}{l}\text { Cold Supply } \\
\text { Chain }\end{array}$ & $\begin{array}{l}\text { - TrCOTERM-based improvements in CMR application. } \\
\text { implementation, measuring, evaluation and development of }\end{array}$ \\
& $\begin{array}{l}\text { scoreboard. } \\
\text { Development of a prototype that allows and enables traceability of } \\
\text { fruit-and-vegetable products whilst on route and its interaction with } \\
\text { logistical companies. }\end{array}$ \\
\hline Storage Nodes & $\begin{array}{l}\text { Design of processes that allow small farmers' groupages to access } \\
\text { Cold Supply Chain transport services in the best conditions. }\end{array}$ \\
\hline ICTs & $\begin{array}{l}\text { - Application in the traceability of fruit-and-vegetable products. } \\
\text { - Application in transport safety. }\end{array}$ \\
& $\begin{array}{l}\text { - Application in the fruit-and-vegetable sector and cold chain. } \\
\text { - Development under open systems. }\end{array}$ \\
\hline
\end{tabular}

\section{Conclusions}

Alongside the main objective of the PROCONET project, to achieve comprehensive traceability of fruit-and-vegetable transport with controlled temperature (in a collaborative network organization), the research team is pursuing a set of long-term goals which, once the project is completed, may be applied to different areas, depending on the type of enterprise and the business sector addressed:

- The project's consortium has established as a challenge to demonstrate the feasibility of the electronic CMR and its legal implications. If it proves to be feasible, the challenge is to propose the different Spanish institutions the modification of the current European normative and INCOTERMS agreements.

- Road export companies would be greatly interested in the results of the prototyping oriented to "on-route transport" because it is a constant source of conflict between logistic operators, customers and insurance companies.

- Logistics companies in the fruit-and-vegetable sector and in other sectors also working in the cold supply chain will have a great interest in the results of the parameterization of traceability, motivated by option to know the actual characteristics of how their transport has been carried out. 
- Small farmers, the most common users of groupages, will be supplied the possibility to incorporate the added value of traceability of their products, which is usually restricted to and monopolized by large companies.

- National transport companies will be motivated to incorporating the technology involved in the prototype, to be developed in this project. This technology will initially involve investment in equipment and facilities, but it will mean an added value and differentiating feature against competition from foreign transport.

\section{References}

1. Benner, M., Geerts, R., Linnemann, A., Jongen, W., Folstar, P., Cnossen, H.: A chain information model for structured knowledge management: towards effective and efficient food product improvement. Trends. Food. Sci. Tech. 14, 469-477 (2003)

2. Camarinha-Matos, L., Pantoja-Lima, C.: Cooperation coordination in virtual enterprises. J. Intell. Manuf. 12, 133-150 (2001)

3. Camarinha-Matos, L., Afsarmanesh, H.: Collaborative networks: a new scientific discipline. J. Intell. Manuf. 16, 439-452 (2005)

4. Camarinha-Matos, L., Afsarmanesh, H.: A comprehensive modeling framework for collaborative networked organizations. J. Intell. Manuf. 18, 529-542 (2007)

5. Camarinha-Matos, L., Afsarmanesh, H., Galeano, N., Molina, A.: Collaborative networked organizations - Concepts and practice in manufacturing enterprises. Comput. Ind. Eng. 57, 46-60 (2009)

6. Gómez-Espín, J.M.: Estrategias de innovación en el sector hortofrutícola español y en las empresas encargadas de la logística y transporte de estos productos perecederos. Papeles de Geografía 39, 81-117 (2004)

7. Moe, T.: Perspectives on traceability in food manufacture. Trends. Food. Sci. Tech. 9, 211-214 (1998)

8. Luengo, G.: El sector hortofrutícola español: a la espera de su racionalización (2003), http: / / www. frutas-hortalizas.com

9. Pereira, A., Rabelo, R., Campos, A., Spinosa, L.: Managing distributed Business processes in the virtual enterprise. J. Intell. Manuf. 12, 185-197 (2001)

10. Ros, L., de la Fuente, M.V., Ortiz, A.: Enterprise Engineering versus Cycle Re-Engineering Methods. In: Proceeding of the 13th IFAC Symposium on Information Control Problems in Manufacturing, INCOM 2009 (2009)

11. Sarkar, S., Costa, A.: Dynamics of open innovation in the food industry. Trends. Food. Sci. Tech. 19, 574-580 (2008) 